\title{
Una esperanza matinal: las dimensiones de la luz en Walden
}

\author{
Óscar Figueroa
}

En el presente ensayo se indaga sobre las diferentes ideas e imágenes asociadas con el fenómeno de la luz (el sol, la aurora, el fuego, la primavera, etc.) en Walden, la obra capital de Henry David Thoreau (1817-1862). En este contexto se defiende la tesis de que un sentido particular de continuidad e incluso totalidad prevalece a lo largo del texto alrededor del imaginario de la luz. Así, se propone la categoría de "redefinición" o "depuración" como clave interpretativa para comprender la importancia de la luz en Walden, prestando además atención a las fuentes que Thoreau emplea con el fin de legitimar narrativamente las diferentes dimensiones de la misma. Finalmente, el ensayo establece un nexo entre el proceso depurativo asociado con el imaginario de la luz y la noción de esperanza.

Palabras clave: Henry D. Thoreau; Walden, Thoreau y Romanticismo, imágenes de la luz, luz y religión.

This paper investigates the various ideas and images associated with the phenomenon of light (the Sun, dawn, fire, springtime, etc.) in Walden, the masterpiece of Henry D. Thoreau (1817-1862). In this context, it is argued that a peculiar form of continuity and even totality prevails throughout the book surrounding the imagery of light. The category of "redefinition" or "depuration" is thus put forward as key to understanding the importance of light in Walden, bringing attention at the same time to the sources Thoreau relied upon in order to legitimate narratively its various dimensions. Finally, the essay establishes a link between the depurative process associated with light imagery and the notion of hope. 
KeYwords: Henry D. Thoreau; Walden, Thoreau and Romanticism, light imagery, light and religion.

Fecha de recepción: 20 enero de 2013

Fecha de aceptación: 18 de mayo de 2013 


\section{Óscar Figueroa \\ Universidad Nacional Autónoma de México \\ Centro Regional de Investigaciones Multidisciplinarias}

\section{Una esperanza matinal: las dimensiones de la luz en Walden}

\section{Introducción}

Mucho se ha escrito sobre la extraordinaria capacidad de H. D. Thoreau (1817-1862) para apropiarse literariamente de un amplio repertorio de fuentes (clásicas y modernas, ortodoxas y disidentes, occidentales y orientales, etc.) e integrarlas de manera innovadora, a veces inesperada. Sin duda, Walden, su obra maestra publicada en 1854, constituye un espécimen notable de ese meticuloso proceso de selección textual y reinvención literaria, amalgama que, por otro lado, sería impensable sin el fundamento vital que aporta el "yo" de la experiencia personal, el "yo" de Thoreau mismo como criterio último de validez y profundidad de contenido. Así, cuando se pone Walden al lado de otros destacados productos intelectuales y literarios de la época, resulta evidente que se está ante un caso ejemplar de distinción en la semejanza: Walden brilla con luz propia a partir de ese fondo común de premisas, aficiones e inquietudes que marcaron el rumbo de la literatura estadounidense del siglo XIX.

A los ojos del lector común todo esto no puede sino representar uno de los rasgos más desafiantes del libro: el encuentro con tal o cual imagen súbitamente se desvía del patrón esperado, conduce a un desenlace remoto o de plano se desdice en un tropel de equívocos deliberados. 
Con frecuencia la naturaleza multi-dimensional e incluso contradictoria de Walden nos hace experimentar perplejidad en medio de un laberinto de sentidos.

La ubicuidad y la riqueza semántica de las imágenes que en Walden están asociadas con la luz - el alba, el sol, el fuego, la primavera y muchas otras - conforman uno de esos ricos laberintos. Entonces, en lo que sigue, y el lector perdonará en este caso la irremediable redundancia, trataré de arrojar un poco de luz sobre la luz que destella a lo largo de los diferentes capítulos que componen Walden. En este sentido, defiendo la idea de que a pesar de su aparente disparidad, el imaginario luminoso de Thoreau posee una línea narrativa y un argumento. De manera preliminar me gustaría definir ese sentido de continuidad y aun totalidad, el todo que es la luz, como un proceso de depuración o redefinición. Desde la perspectiva narrativa, tal proceso se despliega siguiendo el curso de las estaciones, el mismo marco que organiza la trama del libro. Desde una perspectiva más conceptual, el proceso se sustenta en un amplio número de referencias canónicas, de la cuales destacaré tres: las de estirpe romántica, las ilustradas y las propias de la religión.

\section{El horizonte romántico-ilustrado}

Dada la importancia que en el libro tiene el mundo natural, el lector de Walden suele sentirse persuadido a simplemente repetir el nexo que con el ideario romántico le ha asignado a Walden la tradición literaria. ${ }^{1}$ Tal reiteración puede ser, sin embargo, engañosa. En efecto, Thoreau considera la naturaleza como fuente de revelación poética y de transformación interior. Es igualmente cierto que esta apreciación conlleva una crítica al racionalismo instrumental ante el cual había cedido en buena medida el espíritu ilustrado desde principios del siglo XIX. Para sustentar su re-

${ }^{1}$ Sobre la peculiar relación de Thoreau con el romanticismo, pueden consultarse, entre muchos otros títulos, J. Mcintosh, Thoreau as Romantic Naturalist: His Shifting Stance toward Nature, New York, Cornell University Press, 1974; R. P. AdAms, "Romanticism and the American Renaissance", en American Literature 23, 1952, 419-432; P. Miller, "Thoreau in the context of International Romanticism", en The New England Quarterly 34-2,1961, 147-159. 
chazo, los pensadores románticos se volvieron a fuentes textuales, cuyo halo de verdad emanase, no casualmente, de su antigüedad. Por ejemplo, las filosofías de los presocráticos, ${ }^{2}$ el inmanentismo de los neoplatónicos y, finalmente, la sabiduría oriental, en especial la de la India. ${ }^{3}$ En todas estas fuentes el romanticismo creyó encontrar valores que ponían en entredicho los dogmas del racionalismo. Una vez más, no es difícil detectar todos estos elementos en Walden. ${ }^{4}$ Pero no hagamos más larga la lista de las certezas compartidas y pasemos a la diferencia decisiva que aquí me interesa resaltar, la que tiene que ver con el motivo de la luz.

Entonces, junto a la deificación poética de la naturaleza, si hay algo que distingue al romántico es el uso de imágenes nocturnas y, por consiguiente, asociadas con el estado onírico y el submundo del inconsciente. El carácter misterioso del universo nocturno se convirtió rápidamente en uno de los símbolos románticos más explorados, tarea sobre todo dirigida a relocalizar la plenitud humana, al margen de los límites establecidos por el llamado Siècle des Lumières que, en la famosa definición de Kant, encarnaba la anhelada madurez intelectual de la humanidad, esto es, la capacidad para la auto determinación, así como para la determinación de las diversas interacciones del hombre con la realidad (a todos los niveles: epistemológico, moral, religioso o estético), todo ello de acuerdo con principios racionales de validez universal, libres

${ }^{2}$ Notablemente, las enigmáticas reflexiones de Heráclito en torno a la physis o naturaleza, concebida como un principio inmanente, en continua transformación, y no obstante más allá de todo.

${ }^{3}$ Recurso facilitado por la gradual recepción textual que de la misma se produjo a partir de la segunda mitad del siglo XVIII gracias a los estudios y traducciones de W. Jones y H. T. Colebrooke, en Inglaterra, y de los hermanos Schlegel, en Alemania. Al respecto véase W. Halbfass, India y Europa, México, Fondo de Cultura Económica, 2013; R. Schwab, The Oriental Renaissance: Europe's Rediscovery of India and the East, 1680-1880, New York, Columbia University Press, 1984, y R. GÉrARD, L'Orient et la pensée romantique allemande, Paris, Didier, 1963.

${ }^{4}$ Sobre tales influencias pueden hallarse numerosas alusiones en la bibliografía dedicada a la relación de Thoreau con la religión india. Mucho menos es, sin embargo, lo que se ha escrito sobre una posible influencia de la filosofía presocrática y neoplatónica. En cuanto al orientalismo de Thoreau pueden consultarse A. VersLuIs, American Transcendentalism and Asian Religions, Oxford, Oxford University Press, 1993, en especial el cap. 3; R. K. Dhawan, Henry David Thoreau. A Study in Indian Influence, New Delhi, Classical Publishing Company, 1985, y más recientemente P. FrIEDRICH, The Gita within Walden, New York, sunY Press, 2008. 
de dependencia empírica y de quimeras metafísicas. ${ }^{5}$ Tan encomiable empeño no podía permitirse concesiones fuera de la esfera del intelecto. Lo más noble en el hombre reside en sus propios límites, esto es, en los límites que la razón establece. Ir contra este principio significa perder autonomía, un retorno injustificado al oscurantismo de la religión y sus infundadas creencias. De esta guisa, al apostar por un imaginario más bien nocturno, el romanticismo defendía la idea de que la libertad genuina sólo puede experimentarse una vez que el hombre se rinde ante un poder más vasto, que necesariamente existe fuera del ámbito de la determinación racional. Justo aquí yace la diferencia con la apuesta de Walden, obra en la que no parecen tener cabida ni el rechazo tajante a la Ilustración (incluyendo el rechazo a su variante del siglo XIX, el positivismo) ni el encumbramiento de los secretos de la noche. Como trataré de mostrar, detrás de esta decisión la luz cumple un papel doble y, en última instancia, paradójico. ${ }^{6}$

En suma, si bien Walden contiene algunas experiencias nocturnas significativas, por ejemplo como el momento propicio para pensamientos nobles, ${ }^{7}$ o como el escenario que materializa el antiguo imperativo de que sólo se conoce quien primero se ha perdido a sí mismo, ${ }^{8}$ la relevancia de éstos y otros pasajes en los que se asoma la noche en

${ }^{5}$ Aquí las líneas con las que Kant abre su famoso manifiesto Beantwortung der Frage: Was ist Aufklärung?: "[Aufklärung] ist der Ausgang des Menschen aus seiner selbst verschuldeten Unmündigkeit. Unmündigkeit ist das Unvermögen, sich seines Verstandes ohne Leitung eines anderen zu bedienen. Selbstverschuldet ist diese Unmündigkeit, wenn die Ursache derselben nicht am Mangel des Verstandes, sondern der Entschließung und des Mutes liegt, sich seiner ohne Leitung eines andern zu bedienen".

${ }^{6}$ Para un acercamiento a la noción de paradoja en Walden resulta útil J. MoLDENHAUER, "Paradox in Walden", en Twentieth Century Interpretations of Walden, R. Ruland (ed.), Englewood Cliffs, New Jersey, Prentice Hall, 1968, 73-84.

7 "The Ponds", 174-175: "It was very queer, especially in dark nights, when your thoughts had wandered to vast and cosmogonal themes in other spheres, to feel this faint jerk, which came to interrupt your dreams and link you to Nature again". Todas las referencias a Walden pertenecen a la edición definitiva de J. Lyndon Shanley (Princeton, Princeton University Press, 1971). Con el fin de facilitar la identificación de las referencias en otras ediciones incluyo, además de la página, el título del capítulo correspondiente.

8 "The Village", 171: "Not till we are lost, in other words, not till we have lost the world, do we begin to find ourselves, and realize where we are and the infinite extent of our relations". 
nada se compara, sea en número o impacto, con la que posee la luz. Más aún, como veremos, la función principal de la noche en Walden tiene que ver con su equivalente estacional, el invierno, cuyo valor y simbolismo descansa precisamente en dar cobijo y protección a la luz que dormita en su seno de hielo, permitiendo entonces su regeneración. De principio a fin es la marcha transformadora de la luz la que dicta la pauta, quitándole a la noche el privilegio de la experiencia culminante. Esa visión, la visión final a la que nos empuja de manera consistente la narrativa de Thoreau, está reservada a las primeras horas del día, a los primeros jirones de luz sobre un firmamento sin mácula. No debe sorprender entonces que Walden, el lago, sea definido con un laconismo que roza en tautología como un lago de luz, ${ }^{9}$ o que Walden, el libro, esté asediado por imágenes luminosas desde su inicio epigráfico hasta su última línea. ${ }^{10}$ Los extremos de este movimiento alrededor de la luz no suponen, sin embargo, una reiteración de lo mismo, la descripción de un viaje uniforme que retorna sin contratiempos adonde comenzó. Aunque parecen evocar una misma luz, principio y fin están mediados por una transformación de gran alcance.

\section{La luz como talaria}

Anunciada por el cantar del gallo, la primera aurora de Walden se dilata por la boscosa geografía de Concord, que desnuda el profundo estupor intelectual que condena a sus habitantes, los vecinos del propio Thoreau, a entregar su vida a la búsqueda de metas vanas. La mañana crece entonces con un fulgor claramente positivista; su mensaje resuena con sonoros ecos ilustrados: ¡Despierta! Ten el valor suficiente para superar tu amnesia. El naturalista, el explorador y el clasicista son las grandes

9 "The Ponds", 199: "White Pond and Walden are great crystals on the surface of the earth, Lakes of Light".

${ }^{10} \mathrm{El}$ epígrafe: "I do not propose to write an ode to dejection, but to brag as lustily as chanticleer in the morning, standing on his roost, if only to wake my neighbors up". Las líneas finales: "The light which puts out our eyes is darkness to us. Only that dawns to which we are awake. There is more day to dawn. The sun is but a morning star" ("Conclusion”, 333). 
figuras que encarnan las demandas de este tipo de luz. Su misión es una y la misma: elevar al ignorante a las certezas de la razón. Confianza absoluta en el poder redentor del intelecto, una curiosidad científica insaciable, respeto por la literatura canónica, todos estos elementos trabajan juntos para destruir la ignorancia del mundo, entendida como una incapacidad para conocer las leyes de la Naturaleza. ${ }^{11}$ Su combinación forma el antídoto que, aplicado en generosas dosis, puede curar la enfermedad de las creencias míticas y las infantiles aspiraciones metafísicas. ${ }^{12}$

Tal vez el símbolo que mejor condensa la luz ilustrada de Walden es talaria, en el sentido igualmente ilustrado, moderno, que Thoreau le da a la insigne palabra latina en "Baker Farm" (209), esto es, como "cultura" o "educación". ${ }^{13}$ Tradicionalmente, los talaria, sandalias aladas de mensajeros divinos como Hermes o Iris, simbolizan una trascendencia más bien mística o religiosa, lo que en el horizonte clásico no necesariamente significa un cambio o un mejor tipo de vida a partir tan sólo de los recursos que ofrece el intelecto. ${ }^{14}$ De ahí, entonces, el calificativo de "moderno" en el contexto de Walden.

La tarea es, desde luego, tan diversa como los muchos tipos de ignorancia que una luz así está llamada a difuminar. Por ejemplo, trae no sólo un mensaje de redención social para los inmigrantes irlandeses, sometidos a toda clase de abusos ("Baker Farm", 201-209), sino además certeza moral para la humanidad ("What I have observed of the pond is no less true in ethics") ("The Pond in Winter", 291). Talaria es el símbolo luminoso que abre las puertas de ese plano regido por Leyes Superiores, ${ }^{15}$ y nos otorga el valor para domesticar las fuerzas brutas de

${ }^{11}$ Cfr. "The Pond in Winter", 290-291.

${ }^{12}$ Leemos por ejemplo en "The Pond in Winter", 287: "It is remarkable how long men will believe in the bottomlessness of a pond without taking the trouble to sound it [...] I am thankful that this pond was made deep and pure for a symbol. While man believe in the infinite some ponds will be thought to be bottomless".

${ }^{13}$ Cfr. C. Anderson, The Magic Circle of Walden, New York, Holt, Rinehart and Winston, 1968, cap. 5.

${ }^{14} \mathrm{Al}$ respecto véase, por ejemplo, J. CHEvalier, Dictionary of Symbols, Paris, Robert Laffont, 1982.

${ }^{15}$ Véase sobre todo el capítulo con el mismo nombre, "Higher Laws", 210-222. Útil en este contexto es J. Pickard, "The Religion of 'Higher Laws", en Twentieth Century Interpretations of Walden, R. Ruland (ed.), Englewood Cliffs, New Jersey, Prentice Hall, 1968, 85-92. 
la naturaleza ("Nature is hard to be overcome, but she must be overcome") ("Higher Laws", 221); es el símbolo que nos invita a reconocer que ciertos cambios no son sólo deseables sino además posibles y aun inminentes; el símbolo que le infunde a las cálidas brisas del estío el poder de una transformación decidida de antemano, concedida desde siempre.

\section{La luz preservada}

La llegada del invierno pone en marcha un proceso de recogimiento a tres niveles distintos, aunque estrechamente vinculados: hombre, naturaleza y luz. Entonces, tal como Thoreau se refugia en su cabaña por días y noches, morada concebida como una extensión de su cuerpo, así también el lago, ahora cubierto por una gruesa capa de hielo, habrá de replegarse sobre sí mismo. En sus vernales entrañas se preservan, sin embargo, el calor y el esplendor de la luz solar bajo las formas caprichosas del fuego. El aparente letargo exterior no es, pues, sinónimo de inercia u ocio reales. A estas alturas desconocemos la naturaleza exacta y el significado de aquello que se está gestando en la intimidad del oscuro invierno, pero al igual que el hombre medieval, cuya profana mirada debía contentarse con descifrar a la distancia los signos elusivos de los milagros que acontecían en el laboratorio del alquimista (olores, sonidos, vapores), nosotros también tenemos la oportunidad de espiar los signos que confirman que la luz de Walden no sólo no se ha extinguido, sino que además, sigilosa pero puntualmente, está extendiendo su dominio a las esferas reservadas a los dioses:

When the villagers were lighting their fires beyond the horizon, I too gave notice to the various wild inhabitants of Walden vale, by a smoky streamer from my chimney, that I was awake.

Light-winged Smoke, Icarian bird,

Melting thy pinions in thy upward flight

Lark without song, and messenger of dawn $[\ldots]$

Go thou my incense upward from this hearth,

And ask the gods to pardon this clear flame

("House-Warming", 252). 
Entonces, a la manera de los peces que no han dejado de agitarse al fondo del lago congelado, o de modo semejante al solitario búho que medita sobre la punta de un silencioso árbol nevado, aguardando "el amanecer de su día" ("Former Inhabitants; and Winter Visitors", 266), la luz exhortativa de las soleadas mañanas de ayer, las mañanas del frenesí ilustrado, tras haber entrado a la cabaña invernal y haber asumido el color y la forma del fuego, también medita en espera del momento propicio para revelar su esplendor congénito, para volver a ser toda la luz y una nueva luz.

\section{La luz como revelación}

After a still winter night I awoke with the impression that some question had been put to me, which I had been endeavoring in vain to answer in my sleep, as what-how-when-where? But there was dawning Nature, in whom all creatures live, looking in at my broad windows with serene and satisfied face, and no question on her lips. I awoke to an answered question, to Nature and daylight. The snow lying deep on the earth dotted with young pines, and the very slope of the hill on which my house is placed, seemed to say, Forward! Nature puts no question and answers none which we mortals ask. She has long ago taken her resolution ("The Pond in Winter", 282).

Este pasaje es uno de los más celebrados de Walden. En él hallamos de nueva cuenta la centralidad no sólo de la naturaleza, sino más exactamente de una naturaleza sometida a los designios de la luz, enmarcada por las luminiscencias del amanecer. Insertado justo después de las historias de cacería de "Winter Animals", el pasaje tiene un agudo efecto de contrastes. Aun cuando la respuesta de la naturaleza surge de manera silenciosa desde el delicado y casi etéreo velo de la luz matinal, ello nunca ocurre al margen de la vida concreta del bosque. El evento es inesperado y al mismo tiempo prometedor, pues es todavía (still) invierno. ${ }^{16} \mathrm{La}$ luz ha sido preservada en el fuego a lo largo de jornadas

${ }^{16}$ Esto si se lee la palabra en la primera línea en su doble e implícito sentido. M. Bickman sugiere también esta doble lectura para la palabra still. Su análisis sin embargo 
interminables, y esta prodigiosa mañana no sólo anuncia que el día de su renovado esplendor está cerca, sino, más importante aún, que una forma distinta de visión nos aguarda: sutil indicación de que un cambio decisivo en nuestra relación con la naturaleza está teniendo lugar. Las preocupaciones planteadas en primera persona ("I had been endeavoring in vain to answer...") comienzan a desvanecerse en el delicado pero apremiante silencio de la espesura. El individuo parece despertar a una modalidad distinta de luz, no la de su búsqueda personal e inquisitiva de la verdad, centrada en sí mismo. Ésta no es ya la luz que establece fundamentos. La nueva claridad es espontánea, casi absurda; es una luz que trae a la mente los atributos divinos de la rosa mística de Angelus Silesius - sin por qué y abrazando como la única causa de su florecer el hecho mismo de florecer. ${ }^{17}$

El imperativo ascético del libro condensado en la búsqueda de la simplicidad de la vida, una vida "natural", se ve finalmente recompensado por la presencia de una verdad que precede todo esfuerzo, símbolo de máxima libertad más allá del afán humano de conquista. Tal como sucedió con la libertad que la razón es capaz de procurarle al hombre, aquí también la luz desempeña un papel decisivo como imagen literaria y como principio vital. La luz como revelación es la expresión que mejor define esta nueva estación en el itinerario luminoso de Walden. Frente a esta luz, la centralidad de las demandas racionales parece perder peso y aun volverse relativa. Intentar explicar la experiencia es un despropósito. La prioridad es otra. Es cierto que los aspectos ascéticos, contemplativos e intelectuales de Walden crean juntos una predisposición; sin embargo, la visión final no parece pertenecer al individuo que cultivó con esmero cada uno de esos aspectos. Antes bien, la visión le sucede a éste y nada parece contar más que esto. ${ }^{18}$ Desde el punto de

se interesa más por los dos grados de despertar que pueden inferirse del pasaje. $C f r$. Bickman, Walden, Volatile Truths, New York, Twayne Publishers, 1992, 102-103.

17 "Die Rose ist ohne warum; sie blühet, weil sie blühet, sie acht nicht ihrer selbst, frag nicht, ob man sie siehet", en Der cherubinische Wandersmann, t. I, 289.

${ }^{18}$ Desde luego, de manera paralela a esta visión concedida con la gratuidad de las auténticas revelaciones está el asunto de haber sido "elegido" para recibirla, asunto del que Thoreau no sólo estuvo consciente sino que abiertamente identifica en varias partes del libro con su propia y "privilegiada" vida, por ejemplo, al narrar su experiencia del arcoíris en "Baker Farm", 202: "Once it chanced that I stood in the very abutment of a 
vista del individuo, dicha revelación representa asimismo una especie de sacrificio. Afirma Thoreau en "Spring": "At the same time that we are earnest to explore and learn all things, we require that all things be mysterious and unexplorable, that land and sea be infinitely wild, unsurveyed and unfathomed by us because unfathomable" (317-318).

El pasaje contrasta dos dimensiones de la luz en términos epistemológicos. La luz como talaria no sólo converge con un segundo tipo de experiencia luminosa. Antes bien, sobre ella pesa la exigencia de reconocer la superioridad de este nuevo resplandor, o lo que es lo mismo, la exigencia de admitir los propios límites. No es tanto que el pensamiento claro y distinto deba renunciar a su deseo de comprender la naturaleza; se trata apenas de que renuncie a cualquier aspiración absolutista, a su potencial dogmatismo. Así las cosas, mientras que la primera modalidad de conocimiento nos enseña que el lago es un "clear and deep green well, half a mile long and a mile and three quarters in circumference, and contains about sixty-one and a half acres [...]" ("The Ponds", 175), la segunda nos revelará que ese mismo lago:

is a perfect forest mirror, set round with stones as precious to my eye as if fewer or rarer. Nothing so fair, so pure, and at the same time so large, as a lake, perchance, lies on the surface of the earth. Sky water. It needs no fence. Nations come and go without defiling it. It is a mirror which no stone can crack, whose quicksilver will never wear off, whose gilding Nature continually repairs; no storms, no dust, can dim its surface ever fresh $[\ldots]$ ("The Ponds", 188).

Parece entonces que el mismo gallo que una magnífica mañana de verano despertó a sus vecinos con singular ímpetu, vive ahora su pro-

rainbow's arch, which filled the lower stratum of the atmosphere, tinging the grass and leaves around, and dazzling me as if I looked through colored crystal. It was a lake of rainbow light, in which, for a short while, I lived like a dolphin. If it had lasted longer it might have tinged my employments and life. As I walked on the railroad causeway, I used to wonder at the halo of light around my shadow, and would fain fancy myself one of the elect". Asimismo, en las siguientes líneas de "Solitude", 131: "Sometimes, when I compare myself with other men, it seems as if I were more favored by the gods then they, beyond any deserts that I am conscious of; as if I had a warrant and surety at their hands which my fellows have not, and were especially guided and guarded. I do not flatter myself, but if it be possible they flatter me". 
pio despertar sacudido por un canto más decisivo en una mañana más impecable. Sin embargo, al poner de manifiesto los límites de la luz entendida como talaria, Thoreau no defiende la necesidad de buscar una verdad más allá del ocaso, en el horizonte de la noche, la verdad que perseguían sus contemporáneos románticos. Por el contrario, la luz es de nuevo preservada. La sabiduría matinal de Walden sólo se ha depurado, al tiempo que la sed humana de infinito, inicialmente descartada como mera ignorancia, ha sido recuperada.

Los rayos solares que contra todo pronóstico rompen la monotonía del invierno - la luz concebida como imagen de sabiduría reveladaconforman una de las articulaciones más explícitas en el libro con connotaciones profundamente religiosas; de hecho, su alcance descansa en una reinvención del símbolo universal de la luz en las tradiciones espirituales, en particular en aquellas con las que Thoreau estaba más familiarizado: la hinduista, sobre todo en su variante vedāntina, ${ }^{19}$ la griega ${ }^{20}$ y la cristiana. ${ }^{21}$

Este giro radical en el curso de la luz hacia la luz misma supone, pues, un proceso de redefinición basado en la inclusión. Así, de nuevo, en vez de simplemente rechazar las asociaciones modernas de la luz con el pensar racional y, por lo tanto, en vez de sucumbir a la tendencia opuesta de deificar la noche, Thoreau ha depurado su fe en la luz invistiéndola ahora con la refulgencia trascendental de la luz religiosa. Tanto el escritor como el ser humano no han hecho más que llevar hasta sus

${ }^{19}$ En el capítulo "Where I Lived, and What I Lived For", 89, Thoreau cita el siguiente verso del himno a Usha, la diosa védica que preside sobre la aurora: "The Vedas say: "All intelligences awake with the morning"' (el himno pertenece a Rigveda 7.81.2-3). Respecto a una posible influencia del culto solar hinduista, hay otro par de elementos que sería necesario revisar. Por un lado, la más importante de las oraciones védicas, conocida como gāyatrī, la cual celebra a Savitṛ, la deidad que preside sobre el sol naciente; por el otro, la diosa Sarasvatī, deidad matinal que preside sobre la inspiración poética y la claridad intelectual.

20 "I have been as sincere a worshipper of Aurora as the Greeks" en "Where I Lived, and What I Lived For", 88. Basado sobre todo en imágenes asociadas con la luz, Anderson ha estudiado la influencia que sobre Thoreau pudo haber ejercido la religión de Apolo. Cfr. C. Anderson, The Magic Circle of Walden, 248-249.

${ }^{21}$ Son muchas las alusiones cristianas a la luz divina a lo largo del libro, en especial en relación con el sol como símbolo del Resucitado. Sobre este tema, véase ANDERSON, The Magic Circle of Walden, 247. 
últimas consecuencias su creencia "in the promise that each day contains: the earlier, more sacred and auroral hour", la certeza primera que llevó a Thoreau a hacerse un estricto adepto de "the highest of arts", el arte que sólo puede aprenderse a "the most elevated and critical hour": el amanecer ("Where I Lived, and What I Lived For", 89-90).

\section{No cualquier luz, la luz del sol}

Una nueva tentación, tal vez más fuerte incluso que la que sin mayores matices cree hallar en Walden un producto del periodo romántico, surge en esta fase del libro. ¿Dirige Thoreau su historia hacia una experiencia religiosa que trasciende cualquier estadio previo? ¿La finalidad de esas otras luces es, por lo tanto, la de ser meros peldaños en una realización vertical, jerárquica, que termina en el esplendor en lo alto? ¿Excluye la luz religiosa sus reflejos modernos, los de la Ilustración y el romanticismo? Nada más lejos de la verdad narrativa de Walden en general y de su imaginario de luz en particular. Apostar interpretativamente por dicha solución es condenar la obra a la fórmula convencional, al lugar común.

Como sentencia Thoreau justo después de esa memorable "serena/todavía" (still) mañana de invierno, la cual llegó para despejar sus muchas dudas: "Then to my morning work" ("The Pond in Winter", 283). Esta abrupta y profundamente pragmática resolución introduce de nuevo, en el corazón de la revelación estival, la dimensión más básica, elemental de la luz, desdiciendo la expectativa de querer hallar suficiencia, más verdad, en su aspecto trascendente. Asimismo, se trata, desde luego, de una nueva confirmación del otro gran credo del texto, el del valor superlativo de la vida inmediata: lo más valioso de la existencia - y la luz no tiene por qué ser la excepción- acontece todos los días justo frente a nuestros ojos, en medio de los hechos más insignificantes.

La revelación de Walden brilla con la luz de un único sol, el de todos los días, y no con la luz sobrenatural y cegadora de los miles de soles con los que la Bhagavadgìta -el texto que subyace al retiro de Thoreau - intenta verbalizar la experiencia de la forma cósmica del dios 
Krishna. ${ }^{22}$ Desde esta óptica, la luz de Walden es más modesta y no obstante, debido a ese mismo hecho, particularmente poderosa, pues posee la paradójica fuerza de integrar dos mundos, este mundo y el mundo más allá. ${ }^{23}$ Absoluta y perfectísima, infunde además energía a toda clase de criaturas ("Spring", 301-302); hace abundantes los campos ("The Bean-Field", 166) y derrite el hielo ("Spring", 310); es la luz que el lago refleja ("The Ponds", 185) y a la que las aves dirigen sus festivos cantos en primavera ("Spring”, 310).

De nuevo, la estrategia narrativa de Thoreau descansa en el principio de redefinición. Antes, la luz del intelecto había recibido una lección sobre las limitaciones de su poder para transformar y transformarse. Dicha lección suponía además la realidad de una luz más intensa, un esplendor cuyos destellos matinales traen consigo una transmutación más radical. Ahora, esa misma luz de un orden aparentemente superior es identificada con la sustancia material, sensible, de la luz solar. Así, como si anticipara que incluso la luz divina con todo lo que tiene de arquetípica y sublime no está libre del pecado del dogmatismo, Thoreau se atreve a dignificarla por medio de su antípoda terrenal, describiendo entonces un nuevo giro narrativo, que también es un retorno a la inmanencia del mundo.

Cuando se pone atención a cualquiera de estas etapas como unidades independientes en una secuencia más amplia, la impresión es la de un movimiento progresivo de delimitación. Sin embargo, paradójicamente, cuando se cae en cuenta de que la luz es siempre preservada por sí misma, el efecto es el contrario: cada transición representa una forma de expansión: la expansión continua, vital, de la luz en Walden.

22 "If a thousand suns should rise all at once in the sky, such splendor would resemble the splendor of that great Being" (Bhagavadgītā, 11,12).

${ }^{23}$ Cercana tal vez a Thoreau es en este respecto la perspectiva de los neoplatónicos, cuya doctrina precisamente gira alrededor del aspecto inmanente (solar) de la deidad. Pienso, por ejemplo, en Jámblico, quien en sus De Mysteriis $(1,9)$ señala que la luz de Dios se comporta de manera similar a la del sol, de suerte que ambas realidades son comparables. Sobre el conocimiento que Thoreau pudo tener de la tradición neoplatónica en general y de Jámblico en particular, véase ANDERson, The Magic Circle of Walden, $153-155,174$ y $290-292$. 


\section{Una esperanza matinal}

¿Cuál es el hilo que entrelaza cada una de esas etapas, el elemento o sustancia que permite la continuidad y casi perpetuidad de la luz? ¿Sobre qué fondo brilla, sobre qué vacío inciden sus fulgores? Tal vez las respuestas a la obsesión esencialista en medio de la evanescencia de la luz se halle en el profundo sentido de esperanza y redención moral que caracteriza a Walden. ${ }^{24}$ Sirva la sospecha, pues, a manera de conclusión.

En "Spring", Thoreau afirma que al volverse a ese recipiente que contiene la experiencia que la luz matinal es capaz de ofrecer, los hombres tienen la oportunidad de reconocer pureza y perfección en sí mismos y en los demás. ${ }^{25}$ Esta visión optimista termina por imponerse sobre el sentido de pérdida que recorre "Economy", al principio del libro. Podría incluso argüirse que el verdadero punto de partida de Walden es la esperanza. Y es que el recurrente sentido de pérdida en sus páginas no parece surgir de un fondo insensible. La expresión de angustia tiene en realidad la forma de un anhelo por algo que ha sido experimentado y que es posible recuperar. Tan noble certeza permite, por ejemplo, la transición, particularmente difícil, que va del abandono de la mirada racional sobre la naturaleza hacia el reconocimiento de una verdad más alta.

Como he mostrado, Thoreau depositó su confianza en la luz del alba como la compañera simbólica para atravesar esa serie de transiciones debido a las enormes y flexibles posibilidades semánticas que la misma posee. Sin embargo, sin un puente de por medio resulta imposible todo tránsito, me parece que el puente que facilita el despliegue armónico y decidido de la luz es la esperanza. Existen elementos biográficos y propiamente narrativos que así lo indican. En primer lugar, Thoreau no va al lago sin saber qué tipo de experiencia podría encontrar allí. Su decisión fue meditada: Thoreau va al lago a recuperar la época más memorable de su vida, y de ello da cuenta tanto el pasaje ampliamente

${ }^{24}$ Yendo más allá, no hace mucho P. Cafaro propuso toda una ética centrada en la búsqueda de virtud, lo que colocaría a Thoreau al lado de los máximos exponentes occidentales en la materia. Véase CAFARo, Thoreau's Living Ethics, Walden and the Pursuit of Virtue, London, The University of Georgia Press, 2004.

25 "Spring", 314: "In a pleasant spring morning all men's sins are forgiven [...] Through our own recovered innocence we discern the innocence of our neighbors". 
estudiado y comentado en "The Bean-Field" 26 como diversas anotaciones en sus diarios. ${ }^{27}$ Luego, Thoreau está convencido de que nada puede perturbar la prístina esencia que yace al fondo de las cosas, ya sea la esencia de cada individuo, su alma, o la esencia de la creación del mundo, identificada con la Edad de Oro. ${ }^{28}$ Ahora bien, en virtud de que Walden avanza hacia ese pasado glorioso, que es al mismo tiempo la promesa del mañana, la promesa de la mañana, desde ésta, nuestra época de bronce (si se prefiere la cosmología griega), o desde la era de hierro (si uno se siente más próximo a la de la India), resulta absolutamente necesario someterse a un proceso de purificación. Austeridad material, sabiduría popular, disciplina contemplativa, sensualidad poética y conocimientos librescos, cualquiera de estos componentes es bienvenido, siempre y cuando se tenga fe, esperanza, en la dirección correcta, la dirección que la luz señala.

Esta esperanza luminosa - o luz esperanzadora - constituye entonces otra diferencia capital en relación con el imaginario nocturno de los románticos, el mismo que a menudo supuso una visión melancólica y aun trágica de la vida, presagiando de manera significativa el diagnóstico nietzscheano de la tradición intelectual europea. En todo esto estamos forzados a repetir una afirmación inicial de este ensayo, a saber, que Walden es un libro peculiar en lo que tiene de común con las tendencias de su época. Mas ¿cuál es la esencia de los laberintos si no desdecir los lugares comunes, las soluciones fáciles, los juicios que dan la espalda a lo múltiple y complejo? Como sea, si uno se pierde en el laberinto de luz que es Walden siempre habrá una nueva oportunidad

26 "The Bean-Field", 155: "When I was four years old, as I well remember, I was brought from Boston to this my native town, through these very woods and this field, to the pond. It is one of the oldest scenes stamped on my memory".

${ }^{27}$ La entrada más conocida data del 6 de agosto de 1845: "Twenty three years since when I was 5 years old, I was brought from Boston to this pond, away in the country which was then but another name for the extended world for me - one of the most ancient scenes stamped on the tablets of my memory - the oriental Asiatic valley of my world [...] That woodland vision for a long time made the drapery of my dreams" (Journal 2, 173-174).

28 "Spring", 313: "As every season seems best to us in its turn, so the coming in of spring is like the creation of Cosmos out of Chaos and the realization of the Golden Age". 
de resolver el dilema, pues tal como el libro concluye con la misma y al mismo tiempo novísima, esto es, depurada, esperanza con la que dio inició: "There is more day to dawn. The sun is but a morning star" ("Conclusion", 333).

\section{REFERENCIAS}

Bhagavadgītā, trad. S. Radhakrishnan, Delhi, Harper and Collins, 1996.

Hymns of the Rig-Veda, trad. R. T. H. Griffith, Delhi, Munshiram Manoharlal, 1990.

Jámblico, I Misteri Egiziani, ed. y trad. A. R. Sodano, Milán, Rusconi, 1984.

KANT, Immanuel, "Beantwortung der Frage: Was ist Aufklärung?", vol. 6, en Werke in sechs Bänden, W. Weischedel (ed.), Wiesbaden, Insel Verlag, 1956.

Silesius, Angelus, Der cherubinische Wandersmann, Hans L. Held (ed.), Múnich, Carl Hans Verlag, 1949.

Thoreau, Henry David, The Writings of Henry D. Thoreau, Walden, J. Lyndon Shanley (ed.), Princeton, Princeton University Press, 1971.

Thoreau, Henry David, The Writings of Henry D. Thoreau, Journal 2: 18421848, R. Sattelmeyer (ed.), Princeton, Princeton University Press, 1984. 